引用格式: 李子豪, 袁丙兵. 地方政府的雾䨪治理政策作用机制: 政策工具、空间关联和门槛效应 [J]. 资源科学, 2021, 43(1): 40-56. [Li Z H, Yuan B B. Environmental policy mechanism of local governments in the treatment of haze pollution: Policy tools, spatial correlations and threshold effects[J]. Resources Science, 2021, 43(1): 40-56.] DOI: 10.18402/resci.2021.01.04

\title{
地方政府的雾霧治理政策作用机制 政策工具、空间关联和门槛效应
}

\author{
李子豪,袁丙兵
}

(河南财经政法大学国际经济与贸易学院,郑州 450046)

\begin{abstract}
摘 要: 雾霍治理作为“污染防治攻坚战”的重要内容,地方政府作为环境治理的核心主体,有效提升地方政府 环境政策的治霍效果具有重要意义。从政府环境治理的政策工具差异、空间关联和门槛效应的 3 个视角出发,本文 提出了地方政府环境治理降低雾䨓污染的 3 个理论假说,并基于中国 2003-2016年30个省(市、区)和2007-2016 年 217 个城市数据,利用动态空间面板和动态面板门槛计量方法对相关理论假说进行检验。结果表明: (1)政策工具 方面,多数类型的地方政府环境治理政策工具对雾霞污染均存在不同程度的抑制作用,具体来看,地方政府的环保 立法和环保投资降低雾霍污染的效果更显著, 而地方政府环保执法对雾霧污染的抑制作用不甚显著。(2)空间关联 方面,周边地区不同类型的地方政府环境治理政策对本地雾霹污染的影响也存在较大差异,其中,邻近地区环保立 法通过环保政策的协调成本上升加剧了本地雾霹污染; 邻近地区的环保执法虽能降低本地雾霧污染, 但效果却不 显著; 而邻近地区的环保投资通过雾霔治理的空间外溢能显著降低本地雾霍污染。(3)门槛效应方面,地方政府环 境治理对雾䨟污染的影响存在比较显著的门槛效应, 当地区科技水平或城镇化水平较高时,地方政府环境治理能 够有效地降低雾霹污染, 反之则加剧雾霧污染。本文将政府环境治理细分为环保立法、执法与投资 3 种政策工具, 细化了政府环境治理行为对雾霍污染的作用机制, 为政府更进一步完善环境治理体系提供了科学依据。
\end{abstract}

关键词:地方政府;环境治理; 雾霍污染;政策工具;空间关联;门槛效应

DOI :10.18402/resci.2021.01.04

\section{1 引言}

在“绿水青山就是金山银山”理念的指引下,近 年来中国各地绿色发展取得了较大的成效。但是, 中国雾霳污染的形势仍然比较严峻, 《中国生态环

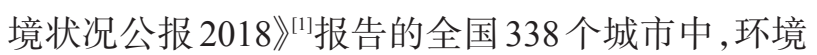
空气质量未达标的城市占比 $64.3 \%$; 习近平同志在 2018 年的全国生态环境保护大会上也明确强调, “坚决打赢蓝天保卫战是重中之重”。当前, 中央政 府对雾䨪治理高度重视, 但由于雾䨪治理的公共产 品属性和中央一地方环保信息的不对称问题的存 在,以及中国现行环境保护法明确规定，“地方各级
人民政府应当对本行政区域的环境质量负责”,因 此雾䨪治理中处于主导地位的仍是地方政府。 2018 年,雾霧治理攻坚战的全国性指导文件“打赢 蓝天保卫战三年行动计划”也明确指出, “地方各级 政府要把打赢蓝天保卫战放在重要位置, 主要领导 是本行政区域第一责任人”,地方政府雾䨪治理的 效果对于能否打赢蓝天保卫战至关重要。

近年来,伴随环境污染防治攻坚战的推进,地 方政府制定了一系列雾䨪治理的专项措施,在雾䨪 治理上投人了大量人力、财力,一定程度地遏制了 大气污染曼延的态势。但是,地方政府雾䨪治理所

收稿日期: 2019-11-29, 修订日期: 2020-09-09

基金项目:国家自然科学基金项目(41871215); 河南省科技厅软科学项目(202400410061); 河南财经政法大学信和・黄廷方青年学者项目。

作者简介:李子豪,男,河南郑州人,副教授,研究方向为环境经济、产业经济。E-mail: lizihao8205@163.com

通讯作者: 袁丙兵,女, 河南南阳人, 硕士研究生, 研究方向为环境经济。E-mail: 277986068@qq.com

http://www.resci.cn 
带来的经济下行压力增加、雾䨪治理的边际成本上 升等诸多问题引起了较多关注 ${ }^{[2]}$ 。因此,在当前背 景下如何有效提升地方政府雾皬治理的成效, 是中 国能否真正打赢蓝天保卫战的关键。长期以来, 地 方政府主要通过环境法律法规出台、环保监督执法 和环保财政支出等政策工具对雾䨪进行治理 ${ }^{[3]}$, 何 种政策工具更加有效? 面对环境治理带来的经济 下行压力增加,地方政府之间在环境治理上存在显 著的策略竞争和地区互动 ${ }^{[4]}$, 加上雾霍污染本身也 具有显著的空间关联, 邻近地区政府的环境治理行 为又会对本地雾䨪治理有效性产生什么影响? 同 时, 考虑到地区经济社会发展水平存在较大差异的 现实, 在什么条件下地方政府环境治理能够更加有 效地减少雾皬污染? 这一系列问题对于地方政府 雾䨪治理成效提升具有重要意义, 但现有研究并未 做出有效回答。因此,在当前大力提升政府环境治 理能力、“污染防治攻坚战”进人攻坚克难阶段背景 下, 本文选择地方政府环境治理如何有效降低雾䨪 污染进行研究, 以期为打赢蓝天保卫战提供理论 借鉴。

\section{2 文献综述}

国内外众多文献对中国雾䨪污染的影响因素 进行了考察, 主要有 3 个方面: 经济性因素、社会性 因素以及政府性因素。

经济性因素。Grossman 等 ${ }^{[5]}$ 提出经典假说—— $\mathrm{EKC}$ 曲线, 即经济增长与环境污染存在倒 $\mathrm{U}$ 型的曲 线关系。因此, 多数学者基于此种思路考察经济增 长如何影响雾霾污染。如, 邵帅等 ${ }^{[6]}$ 对中国 30 个省 (市、区)、Ma等 ${ }^{[7]}$ 对中国 152 个城市的研究发现, 人 均 GDP 与雾䨪污染两者之间存在正 U 型曲线关系; 孙攀等 ${ }^{[8]}$ 利用中国 281 个城市的数据研究发现, 经济 增长与雾䨪之间存在 $\mathrm{EKC}$ 关系, 且中国多数地区尚 处于经济增长加剧雾䨪排放阶段。由于工业生产 是雾䨪污染的重要来源, 且结构因素是污染来源分 析重要部分, 部分学者考察了产业结构的影响。 如, 修国义等 ${ }^{[9]}$ 、徐盈之等 ${ }^{[10]}$ 利用省 (市、区) 数据研究 发现, 第二产业增产显著加剧了雾䨪污染, 而地区 间工业集聚则降低了雾䨪污染; $\mathrm{Li}^{\text {等 }}{ }^{[1]}$ 基于地市层 面的研究也发现了类似结论。城镇化会带来能源
消耗和生产生活模式的变化,众多学者对此比较关 注, 如 Han 等 ${ }^{[12]}$ 研究发现, 由于能源消耗强度高和交 通拥堵等原因, 中国多数地区城区的雾䨪浓度显著 高于城郊地区; 刘晨跃等 ${ }^{[13]}$ 利用 30 个省 (市、区) 的 面板数据发现,城镇化加剧了中国的雾䨪污染; 王 华星等 ${ }^{[14]}$ 利用城市数据发现, 新型城镇化(低碳城市 建设)能够显著降低城市雾䨪污染, 且信息化和人 力资本水平高的城市作用更加明显。对外开放是 中国经济增长的重要动力, 部分学者考察了外商投 资和国际贸易对雾䨪的影响。如曾浩等 ${ }^{[15]}$ 、严雅雪 等 ${ }^{[16]}$ 对 30 个省 (市、区) 的研究发现, FDI 显著增加了 中国雾䨪污染; 刘修岩等 ${ }^{\left[{ }^{17]}\right.}$ 对省 (市、区) 层面的研究 发现, 重工业出口贸易加剧了雾䨪污染, 而高科技 产品出口则相反。该领域多数研究以传统的规模 效应、结构效应为主要方向, 研究思路仍局限于经 济因素本身,对雾䨪治理的重要主体一一地方政府 的关注不足，或者在作用机制中极少涉及地方政府 治理行为的影响。

社会性因素。雾䨪污染作为社会公众普遍关 注的现实问题,众多社会性因素也会对其产生影 响。环保公众参与方面, Wang 等 ${ }^{[18]}$ 利用部分代表性 城市的调研发现,在雾䨪信息充分披露的情况下， 公众对于雾霾治理的支付意愿很强; 初钊鹏等 ${ }^{[19]}$ 利 用演化仿真研究发现,公众参与以第三方监督的形 式改变了地方政府治理预期,有利于雾䨪治理。社 会與论的影响, 吕长明等 ${ }^{[20]}$ 对地市层面的研究发现, 地区雾霾與论爆发通过推动地区工业化转型而降 低雾䨪污染, 且此种影响在发达地区比较显著; 李 欣等 ${ }^{[2]}$ 对省 (市、区) 层面的研究发现, 中西部地区雾 皬污染的缓解一定程度上依赖于网络舆论, 但东部 地区效果却不明显。交通行为影响方面,王卉娅 等 ${ }^{[22]}$ 利用 45 个城市的高德拥堵延时指数衡量交通 拥堵水平, 并考察其对雾䨪污染的影响, 发现交通 拥堵加剧了雾䨪污染, 而城市职住平衡有助于缓解 交通拥堵带来雾霾污染的减少; Xie 等 ${ }^{[23]}$ 利用 281 个 城市的面板数据发现, 城市交通流密度与城市雾䨪 污染之间存在倒 U 型曲线关系, 且此种关系只在大 中型城市比较显著。其他因素方面,钱振华等 ${ }^{[24]}$ 、彭 本红等 ${ }^{[25]}$ 分别考察了社会伦理意识、民间资本对雾 
皬污染的影响, 研究发现责任伦理意识和民间资本 的提升均能够有效地提高雾䨪治理效果。该领域 研究更多地集中于社会公众行为或态度对雾䨪污 染治理的影响, 跳出了雾䨪治理主要靠经济转型的 传统思维框架。但是, 相关研究对社会公众治䨪作 用与政府雾䨒治理政策之间的互动联系分析比 较少。

政府性因素。雾雽治理具有典型的外部性,政 府在雾䨪治理中发挥主导作用。由于政府雾䨪治 理需要大量的资金投人, 而作为雾䨪治理主体的地 方政府财力长期受制于中央-地方财政分权的影 响, 因此众多学者关注财政分权对雾䨪污染或治理 的影响。如李根生等 ${ }^{[26]}$ 通过对 29 个大中城市的考 察发现,大中城市具有更高的财政自主权,激励了 地方政府大力进行雾霧治理; 黄寿峰 ${ }^{[2]}$ 利用 29 个省 级数据进行检验,财政分权反而抑制了本地、邻近 地区的雾䨪治理效果。由于地方政府之间存在显 著的“锦标赛”式经济竞争, 这也会对地区雾䨪污染 和治理产生显著影响。吴勋等 ${ }^{[28]}$ 基于 73 个地市的 研究发现, 以外资引人为导向的地方政府竞争显著 抑制了雾霾污染; 刘华军等 ${ }^{[29]}$ 基于 30 个省(市、区)的 研究发现,在经济利益为政绩考核主要标准的背景 下,地方政府之间会出现为争夺经济资源而放松雾 䨪治理的 “逐底竞争”。一些学者则关注具体雾䨪 控制政策的效果,如石庆玲等 ${ }^{[30]}$ 对中国 189 个城市 的研究发现, 各地 “两会”召开会对当地雾䨪污染产 生了比较显著的抑制作用; Chen 等 ${ }^{\left[{ }^{[1]}\right.}$ 利用主成分测 算比较、李小胜等 ${ }^{[22]}$ 利用断点回归研究发现, 北京奥 运会限行和 G20 期间的环境政策十分显著地降低 了雾䨪污染; 孙坤金鍅 ${ }^{[33]}$ 利用断点回归考察了北京机 动车排放标准提升对当地雾雺污染的影响, 研究发 现该政策效果并不显著; 罗知等 ${ }^{[34]}$ 运用双重倍差法 对 283 个城市的研究发现, “大气十条”政策显著降 低了北方地区集中供暖带来的雾䨪污染。现有政 府性因素的研究多关注于具体治䨪政策效应的分 析, 或者探讨地方政府经济竞争行为对雾䨪治理的 影响, 但是对于地方政府不同类型雾霧治理策略效 果的差异、地方政府不同治䨪政策之间的空间互动 和作用条件, 少有研究进行系统分析。

综上所述, 国内外学者对于中国雾䨪污染影响
因素的研究在经济方面、社会方面、政府方面较为 全面,为后续进一步研究提供了一定基础,但也存 在部分问题有待深人: 分析思路上, 经济因素和社 会因素自身作用的思考比较多,将地区经济发展、 社会公众行为与地方政府雾雺治理策略有机结合 的分析较少。政策作用上,具体雾䨪治理政策的微 观效应关注比较多,而地方政府不同环境治理策略 的影响和差异关注较少,地区之间不同环境治理策 略的动态空间关联和地区条件差异所导致的门槛 效应研究也很少见到。研究层面和变量选择上, 现 有多数研究选择省区或城市单一层面、某种单一的 雾霧污染指标进行实证考察估计,研究的系统性和 客观性有待进一步提升。因此,本文基于中国 2003-2016年30个省(市、区) 和 2007-2016年 217 个城市的相关面板数据, 从地方政府环境治理政策 工具差异、空间关联和门槛效应等 3 个角度,考察地 方政府环境治理政策对雾䨪污染的影响。与以往 研究相比,本文在以下 3 个方面有所改进:第一,理 论机制上,通过对现有研究和现实的梳理分析, 分 别从政策工具、地区关联和门槛效应 3 个角度构建 了地方政府环境治理对雾䨪影响的理论假说,拓展 了研究领域。第二, 研究方法上, 考虑到雾霧污染 存在的时空地理依赖问题, 以及中国地区之间经济 社会发展水平的差异, 同时采用动态空间计量和动 态面板门槛来考察地方政府环境治理政策的影响 效果, 研究结论更加科学可靠。第三,研究指标和 研究层面上,通过手工搜集统计研究期内近 10 年 200 余地市的政府环保财政支出数据,使得从地市 层面考察地方政府环境治理对雾䨪污染的影响成 为可能; 同时从 30 个省 (市、区) 和 217 个地市层面 进行考察,避免了不同层级差异对地方政府环境治 理的雾霯控制效应的影响,更加系统全面。

\section{3 理论机制与研究假说}

为了回答前文提出的地方政府何种环境治理 政策工具更加有效、地方政府环境治理对雾䨪污染 的影响存在何种地区空间互动、何种条件下地方政 府环境治理能够更有效地减少雾䨪污染等 3 个重要 现实问题,理论假说部分从地方政府环境治理的政 策工具、空间关联和门槛效应 3 个角度,分别探讨地 方政府环境治理政策对雾䨪污染的影响作用机制。 


\section{1 政策工具差异}

在当前环境治理攻坚战不断深人的阶段, 地方 政府治理的多类型模式也逐渐成熟, 在宏观层面, 地方政府主要通过环保立法、环保执法和环保投资 等不同政策工具为社会提供公共物品 ${ }^{[3]}$; 在微观层 面, 地方政府主要通过与企业及社会公众的互动调 节来弥补宏观政策的功能缺失 ${ }^{[35]}$ 。整体来看, 由于 不同政策工具进行雾䨪治理的作用机制和作用条 件存在差异,其效果也会有所不同。

环保立法的影响。近年来在中国环保立法中， 针对雾䨪治理立法的数量和强度都有所增强, 首 先, 2006 年以来, 中央政府已将节能减排情况明确 纳人了地方政府考核标准,并通过雾䨪立法进行了 责任创新以明确污染责任, 大力推动雾䨪治理的联 防联治, 辅以环保督查组核查和环保约谈监督雾霾 治理情况,一定程度上增强了政府、企业以及公众 三方各自的雾䨪治理责任意识 ${ }^{[36]}$ 。其次, 最新的《大 气污染防治行动计划》 ${ }^{[37]}$ 明确要求“2017 年全国地 级及以上城市可吸人颗粒物浓度比 2012 年下降 $10 \%$ 以上”, 伴随此类对大气治理提出明确要求的法 律规章文件陆续出台,地方政府雾霾治理的刚性约 束不断加强。最后, 利用北大法意数据库统计发 现, 2013-2018 年全国范围大气污染治理法律法规 占全部环保法律法规数量的比例为 $12.28 \%$, 远高于 此前 5 年 $4.91 \%$ 的立法数量占比; 而且, 随着法律法 规的完善和实际可执行、可操作性的增强, 环保立 法能够更好地对中国雾霍治理产生积极影响。

环保执法的影响。首先, 由于雾䨪污染存在显 著的空间外溢, 且会随季节变化产生规律性波动, 加上中国供电供暖对传统生产模式和煤炭能源的 刚性依赖、机动车尾气排放控制等技术难题的存 在 ${ }^{[33,34]}$, 环保执法很难打破雾䨪治理的能源和技术 瓶颈。其次, 环保执法与经济增长之间冲突。由于 当前中国多数地区的经济增长模式仍以粗放型为 主, 过于严格的环保执法将对地方经济增长产生一 定抑制作用, 这一冲突在当前经济增长显著放缓的 背景下会进一步加剧。在经济增速作为地方政府 考核主要评价指标和经济增速普遍放缓的背景下, 雾䨪治理与当地经济发展之间的矛盾日益凸显: 地
方政府在面对隶属于自身的环保部门以及能对自 身带来巨大经济利益的部分排污企业时,地方环保 执法不可避免存在环保执法盲区 ${ }^{[38]}$, 环保执法对部 分雾皬污染企业的治理效果可能有限。最后, 虽然 近年来环保执法部门的独立性有所增强, 但由于环 保执法的专业性,环保执法过程中权利制约监督的 有效性不足,地方政府环保执法被监督企业俘获的 情形不同程度存在 ${ }^{[4]}$,也会降低环保执法的雾䨪治 理效果。当然,伴随 2016年以来环保机构监测监察 执法垂直管理制度的逐步推进，地方环保监测权限 的“上移”和环保执法权限的“下沉” ${ }^{[39]}$, 以及中央环 保督察组对地区环境保护督查的加强,地方环保执 法在雾䨪治理方面的有效性也会有所增强。

环保投资的影响。首先,近年来中央和地方政 府对环保投资十分重视,国家财政中环境保护的支 出金额从 2007 年的 995 亿元增加到 2018 年的 6352 亿元, 占比也由原来不足 $2 \%$ 提高到 $2.8 \%$, 环保投人 规模稳步提升; 而且, 由于雾䨪污染的严峻性和政 府重视程度的提升,各地方政府纷纷出台雾䨪治理 专项财政资金支持,以河北省为例, 2014年雾霉治 理专项资金已经达到环保总支出的 $20 \%$ 以上。其 次, 除了对环境污染源的直接治理,地方政府的环 保支出多用于企业技术改造升级、淘汰高能耗和高 污染设备的财政补贴 ${ }^{[40]}$,这将带来地区绿色技术水 平的持续进步,也有利于地区之间治污技术的外溢 扩散, 为地区绿色转型和雾䨪治理提供长期动力支 撑。最后,伴随中央和地方政府对于环境保护投人 的加大, 雾䨪治理专项投资的不断加强, 企业和广 大社会公众的环保观念和环保意识会不断增强,雾 皬污染防治的市场规模会不断扩大,也会吸引更多 的社会资本的流人 ${ }^{[41]}$,雾䨪污染的治理效果会不断 凸显。

基于以上分析,提出理论假说 1 : 地方政府环保 立法和环保投资对雾皬污染的治理效果会比较显 著，而地方政府环保执法的治理效果可能不甚 明显。

\section{2 空间关联效应}

雾皬污染作为当前地方政府环境治理的工作 重点,会因地理或气象原因而存在显著的空间关联 效应 ${ }^{[2]}$,地方政府环境治理对雾皬污染的控制成效 
也不可避免地受到空间关联影响。具体来说, 主要 受以下三方面影响。第一, 雾䨪污染的空间溢出来 看, 由于雾䨪的主要污染物 PM2.5 与传统污染存在 差异, 主要由极度细微的颗粒物组成, 地区之间的 传播性极强, Liu等 ${ }^{[42]}$ 发现本地区雾䨪污染的恶化会 对周边甚至更远地区的雾霾浓度产生负面影响。 因此, 本地政府雾䨪治理成效必然会对邻近地区产 生影响。第二, 财政分权导致的地方政府竞争来 看, 黄寿峰 ${ }^{[2]}$ 认为财政分权使得地方政府在环境治 理方面出现了 “竞优”现象, 能够通过本地政府环境 规制标准的提升来促进周边地区政府环境规制强 度和政府雾䨪治理意识增强; 相反, 邵帅等 ${ }^{[6]}$ 认为, 在中国式财政分权下,本地政府环境保护支出可能 通过“破坏性规则竞争”现象和 “竞次”现象导致周 边地区环境保护投人减少,地方政府会为了经济发 展放松环境监管,不利于地区雾䨝污染控制。第 三,雾䨪污染治理的策略性博亦来看, 雾䨪的空间 外溢和关联性使得其有效治理必须通过区域性的 联防联治实现, 而地方政府在雾䨪联防联治时不同 程度地存在政策性博弯或“搭便车”行为, 部分地方 政府会通过分享邻近地区雾䨪治理的正外部性而 减少本地治理投资, 或者在地域边界建立高污染企 业以共享雾䨪治理和经济发展的红利 ${ }^{[30]}$ 。

基于以上分析,提出理论假说 2 : 地方政府环境 治理对本地雾皬的治理成效, 会受到邻近地区政府 环境治理的影响。

\section{3 门槛效应}

在地方政府环境治理过程中, 受到各地不同的 经济发展水平、地方习俗以及社会制度等因素影

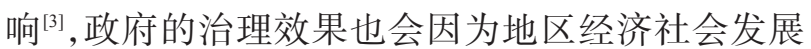
水平的差异而存在门槛效应 ${ }^{[43,44]}$ 。中国是发展中大 国,地区经济社会发展差距明显,地方政府环境治 理的减䨪效应也很有可能存在类似的门槛效应。 由于当前雾䨪污染的产生, 一定程度是中国城镇 化、工业化进程快速推进的自然结果 ${ }^{[13]}$, 而雾霧的有 效治理则需要地区技术水平的有效提升 ${ }^{[45]}$, 本文主 要从地区科技水平和城镇化两个角度对政府雾䨪 治理的门槛效应进行分析。

地区科技水平门槛效应。首先, 环境规制标准
的影响。Lovely 等 ${ }^{[46]}$ 的研究表明, 只有地区技术水 平发展到较高水平,地方政府才会制定较高的环保 标准或较为严格的环保政策; 这同样意味着, 只有 当地区技术水平比较高时,地方政府的雾䨪治理标 准和实际力度才会加强, 雾䨪治理实际成效才会更 好。其次, 经济增长模式的影响。一般来说, 只有 地区技术水平达到较高程度, 地区产业结构优化升 级、经济绿色转型进程才能够有效进行, 而只有地 区经济实现了绿色转型,地方政府为了经济发展而 放松环境治理(雾䨪治理)的“竞次”竞争现象才能 真正避免,政府雾䨪治理成效才可能真正提升。第 三,环保技术市场化的影响。环保技术发展对于平 衡经济发展与雾䨪治理之间矛盾至关重要, 但只有 本地技术市场化程度较高时,才能避免创新要素投 人的低效率和绿色技术研发的扭曲 ${ }^{[47]}$, 最终提升地 方政府雾䨪治理的效率。而另一方面, 只有地区科 技水平较高、绿色技术比较成熟时,环保技术市场 制度才能有效建立并发挥作用。

基于以上分析,提出理论假说 3 : 只有地区科技 水平达到较高程度,地方政府雾雽治理的成效才会 比较显著。

地区城镇化门槛效应。首先, 城镇化提高通常 与地区经济发展同步,而 Grossman 等 ${ }^{[5]}$ 的经典研究 表明, 只有地区收人水平达到一定程度, 民众强劲 的环保需求才会倒逼政府进行有效的环境污染治 理。这也意味着, 只有地区城镇化水平达到较高程 度时,地方政府才会有足够的雾䨪治理动力, 效果 才会比较显著。其次,陆铭等 ${ }^{[48]}$ 的研究表明,伴随地 区城市规模或城市集聚加强,环境污染治理的规模 经济效应会不断凸显。同样,伴随城镇化水平提 升,地方政府雾皬治理投资规模效应和有效性也会 有所提升。最后,城镇化会带来当地产业和人口的 明显集中,这使得雾霧污染的负面危害将更加暴 露,当地公众对环境改善的诉求和行为意识都会显 著增强 ${ }^{[3,13]}$,社会公众对政府环境治理的监督也会更 强, 从而倒逼地方政府提升雾䨪治理效果或效率。

基于以上分析, 提出理论假说 4 : 只有地区城镇 化水平达到较高程度,地方政府雾䨪治理的成效才 会比较显著。 


\section{4 研究方法与数据来源}

\section{1 基本模型和变量说明}

Grossman 等 ${ }^{[5]}$ 关于环境经济学的经典研究认 为,应当主要从规模效应、结构效应和技术效应 3 个 方面对环境污染的影响因素进行分析。为对以上 理论假说进行检验，基于 3 种效应的经典分析框架， 借鉴邵帅等 ${ }^{[6]}$ 、黄寿峰 ${ }^{[27]}$ 等的研究因素选择, 本文计 量模型基本框架如下:

$$
\begin{aligned}
\operatorname{smog}_{i, t}= & \alpha_{0}+\alpha_{1} \operatorname{gov}_{i, t}+\alpha_{2} e y_{i, t}+\alpha_{3} e y_{i, t}^{2}+ \\
& \alpha_{4} \operatorname{sci}_{i, t}+\alpha_{5} s_{i, t}+\alpha_{6} u r b_{i, t}+\alpha_{7} f d i_{i, t}+ \\
& \alpha_{8} h_{i, t}+\alpha_{9} d e n_{i, t}+\varepsilon_{i, t}
\end{aligned}
$$

式中: smog 表示雾䨪浓度; gov 表示地方政府环境 治理; $e y$ 表示经济发展, $e y^{2}$ 为经济发展的平方项; $s c i$ 表示科技水平; $s$ 表示产业结构; $u r b$ 表示城镇化 水平; $f d i$ 表示外资水平; $h$ 表示人力资本水平; $d e n$ 表示人口密度; $i 、 t$ 表示地区、年份; $\alpha_{0}$ 表示常数, $\alpha_{1}-\alpha_{9}$ 表示各影响因素系数; $\varepsilon$ 表示随机扰动项。 其中, ey 主要考察规模效应, $s$ 考察结构效应, 其他 变量则纳人技术效应框架考察。

雾䨪污染 ( smog) 数据的选择。2013 年之后, 国内部分城市较为系统的官方雾䨪监测数据才开 始出现, 省 (市、区) 层面的雾䨪数据和国内大多数 城市的客观雾䨪数据是难以直接获得的, 也限制了 深人政府环境治理对雾䨪控制效果的实证研究。 借鉴邵帅等 ${ }^{[6]}$ 、黄寿峰 ${ }^{[27]}$ 等的数据来源, 基于美国哥 伦比亚大学发布的全球 PM2.5 浓度年均值的栅格数 据图, 本文利用 ArcGIS 提取了研究期内各省 (市、 区) 和地市的年均雾䨪浓度数据, 分别用 $\operatorname{smog}$ 和 $S M O G$ 表示。

政府环境治理 ( gov ) 数据, 借鉴李子豪等 ${ }^{[49]}$ 的 做法分为 3 种: 本文分别使用环保立法 (law)、环保 执法 ( enf ) 、环保支出 ( inv ) 来系统衡量。其中, 使 用各地方政府在环境保护上所颁布的年度法律法 规数量来表示环保立法 (law); 使用各地方政府环 境保护机构单位工作人员所查处的环保案件数来 表示环保执法 (enf); 使用各地方政府环保财政支 出占一般公共预算支出的比例来表示环保投资 ( inv )。政府环境立法 (law) 主要来源于法律之星 数据库中人大以及政府出台的环境保护法律法规
数量; 环境保护支出 (inv) 数据主要来源于地方财 政年鉴。由于城市层面数据的缺失, 本文未对城市 层面环保立法和环保执法数据进行统计。

$e y$ 代表经济发展, 以人均 GDP 衡量, 省(市、区) 和地市分别为 $e y$ 和 $E Y$ 。多数的雾䨪污染影响因 素分析在 $\mathrm{EKC}$ 框架基础上进行, 邵帅等 ${ }^{[6]}$ 、黄寿峰 ${ }^{[2]}$ 也发现了地区经济发展与雾霧之间存在显著非线 性关系。为了考察经济发展与雾䨪污染之间的非 线性关系, 计量模型中包含人均 GDP 的平方项 $\left(e y^{2}\right) 。 s c i$ 是科技水平, 借鉴田毕飞等 ${ }^{\left[{ }^{[00}\right.}$ 的做法, 用省区和地市科学技术支出占一般公共预算支出 的比重衡量,技术水平是污染影响因素分析技术效 应框架的重要组成部分,也是地方政府雾䨪治理的 支撑手段。 $s$ 是产业结构, 以第二产业增加值占 GDP 比重衡量,省(市、区) 和地市的产业结构分别 为 $s$ 和 $S$; 由于第二产业的能源消耗依赖度较高, 地 区工业化进程通常被认为是雾䨪污染加剧的重要 原因 ${ }^{[9-11]}$ 。 $u r b$ 是城镇化水平, 以地区城镇常住人口 占总人口比重衡量, 省(市、区) 和地市分别为 $u r b$ 和 $U R B$; 城镇化带来的产业变迁、人口集聚以及基础 设施建设都会对地区雾䨪污染产生影响 ${ }^{[13]} 。 f d i$ 是 地区外资水平,分别用 $f d i$ 和 $F D I$ 表示省(市、区) 和地市外资。由于外资进人会对当地环境技术发 展产生重要影响,也是地方政府之间资本或资源竞 争的主要对象,地区外资水平会对当地雾䨪污染产 生重要影响; 借鉴李子豪等 ${ }^{[43]}$ 的计算方法,用各地存 量 FDI 占 GDP 的比重表示利用外资水平。 $h$ 是省 (市、区) 人力资本水平, 用当地人口的平均受教育 年限表示; 城市人力资本 $(H)$ 以当地中学、大学在 校生人数占总人口的比重表示。den 表示人口密 度, 用单位行政区面积的人口衡量, 分别用 $d e n$ 、 $D E N$ 表示省(市、区)、地市的人口密度; 人口的集聚 效应一定程度会对政府环境治理决策产生影响,也 会通过社会活动对地区雾霔污染产生影响。

\section{2 空间杜宾模型和门槛效应模型}

由于地方政府环境治理和雾霳污染都可能会 受到周边地区的影响, 具有空间关联的特征。为了 更好地考察政府环境治理的影响并对理论假说 2 进 行验证, 模型构建必须加人地区空间效应的影响。 
同时, 考虑到雾䨪污染受到地区经济活动、环保政 策执行变化而存在一定的时滞性,计量模型中加人 雾䨪指标的时间滞后项。则本文空间关联角度的 估计模型如下:

$$
\begin{aligned}
\operatorname{smog}_{i, t}= & \beta_{0}+\beta_{1} \operatorname{smog}_{i, t-1}+\beta_{2} \operatorname{gov}_{i, t}+\beta_{3} W_{i, t} \operatorname{gov}_{i, t}+ \\
& \beta_{4} e y_{i, t}+\beta_{5} W_{i, t} e y_{i, t}+\beta_{6} \operatorname{ey}_{i, t}^{2}+\beta_{7} W_{i, t} e^{2}{ }_{i, t}+ \\
& \beta_{8} \operatorname{sc} i_{i, t}+\beta_{9} s_{i, t}+\beta_{10} W_{i, t} s_{i, t}+\beta_{11} u_{r} b_{i, t}+ \\
& \beta_{12} f d i_{i, t}+\beta_{13} W_{i, t} f d i_{i, t}+\beta_{14} h_{i, t}+\beta_{15} \operatorname{den}_{i, t}+ \\
& \beta_{16} W_{i, t} d_{e n}+\sigma_{i, t}
\end{aligned}
$$

式中: $\boldsymbol{W}_{i, t}$ 是一个 $N \times N$ 维空间加权矩阵, 从地理权 重、经济权重以及混合权重 3 个方面研究。地理权 重矩阵 $\boldsymbol{W}_{d}=1 / d_{a b}^{2}, a \neq b$, 否则为 0 ; 经济权重 $\boldsymbol{W}_{e}=1 /\left|g d p_{a}-g d p_{b}\right|, a \neq b$, 否则为 0 ; 混合空间权重 矩阵 $\boldsymbol{W}_{m}=\boldsymbol{W}_{d} \cdot \boldsymbol{W}_{e}$ 。 $\operatorname{smog}_{i, t-1}$ 为雾䨪浓度的时间滞后 项, $\boldsymbol{W}_{i, t} \operatorname{gov}_{i, t} 、 \boldsymbol{W}_{i, t} e y_{i, t} 、 \boldsymbol{W}_{i, t} e y_{i, t}^{2} 、 \boldsymbol{W}_{i, t} s_{i, t} 、 \boldsymbol{W}_{i, t} f d i_{i, t}$ 、 $\boldsymbol{W}_{i, t} h_{i, t} 、 \boldsymbol{W}_{i, t} \mathrm{den}_{i, t}$ 分别为地方政府环境治理、人均收 人、人均收人平方项、产业结构、外资存量、人力资 本以及人口密度的空间滞后项; $\beta_{0}$ 表示常数, $\beta_{1}-$ $\beta_{16}$ 表示各影响因素系数; $\sigma$ 表示随机扰动项。

为了更好地考察地方政府环境治理的空间关 联效应, 解决自变量和因变量本身时间滞后项带来 的影响,本文使用基于动态空间面板估计的动态空 间杜宾模型 (Dynamic Spatial Durbin Model, DS$\mathrm{DM})$ 进行估计。

理论假说 3 和假说 4 提出地区科技水平和城镇 化水平的门槛效应, 为了对相关理论假说进行检 验, 本文采用面板门槛回归方法, 分别将科技水平 和城镇化水平门槛值作为未知变量引人 (1) 式中, 建立地方政府治理雾䨪的分段函数, 并对科技水 平、城镇化水平的门槛值以及门槛效应进行实证分 析。本文假设存在单一门槛效应, 得到如下模型:

$$
\begin{aligned}
\operatorname{smog}_{i, t}= & \delta_{0}+\delta_{1} \operatorname{smog}_{i, t-1}+\delta_{2} \operatorname{gov}_{i, t} I_{i, t}(\mathrm{th} \leqslant \theta)+ \\
& \delta_{3} \operatorname{gov}_{i, t} I_{i, t}(\mathrm{th}>\theta)+\delta_{4} e y_{i, t}+\delta_{5} e^{2}{ }_{i, t}+ \\
& \delta_{6} s_{i, t}+\delta_{7} f d i_{i, t}+\delta_{8} h_{i, t}+\delta_{9} \operatorname{den}_{i, t}+\pi_{i, t}
\end{aligned}
$$

式中: $t h$ 是门槛变量, 即科技水平和城镇化; $\theta$ 为具 体的科技水平和城镇化水平门槛值; $I(\cdot)$ 为门槛值 效应函数; $\delta_{0}$ 表示常数, $\delta_{1}-\delta_{9}$ 表示各影响因素系 数; $\pi$ 表示随机扰动项。多重门槛可以由 (3) 式变 化得来。
与科技水平或城镇化水平进行分组比较研究 相比, 面板门槛估计能够更好地根据数据自身的特 征进行内生分组回归,有效地减少外生分组带来的 主观误差。同时,考虑到政府雾雽治理自身的动态 影响以及解释变量的滞后效应, 本文利用动态面板 门槛进行考察。

\section{3 数据来源和统计性描述}

受到环保执法案件数据和雾䨪卫星图片数据 可得性的限制, 本文中省 (市、区) 层面研究对象为 2003-2016年中国30个省(市、区) (不包括西藏、港 澳台地区,下同); 其中, 由于环保财政支出科目在 2007 年设立,省级政府环保支出统计年份为 20072016年。地市层面政府环境治理指标仅涉及政府 环保支出单一数据, 地市层面研究对象为 20072016年中国大陆除西藏自治区外的 30 个省 (市、区) 和 217 个地级市。涉及到价格的数据, 均以 2000 年 为基期进行不变价格处理。省级政府环境治理数 据主要来源于中国财政年鉴、中国统计年鉴和法律 之星数据库;地市政府环境治理数据主要来源于部 分省区财政年鉴、统计年鉴和地市财政局官网。其 他变量数据主要来源于各地市统计年鉴、中国外商 直接投资发展报告、中国统计年鉴和 EPS 数据库。 表 1 对省(市、区) 和地市所涉及的所有变量进行描 述性统计。由表可知,省级政府与地市政府的环境 治理、PM2.5 浓度等存在着明显差异,研究地区政府 环境治理对雾䨪污染的影响很有必要; 同时, 由于 研究样本的科技水平、城镇化水平也存在比较显著 的地区差异，从地区科技和城镇化水平考察地方政 府环境治理的门槛效应存在一定合理性。

\section{5 结果与分析}

\section{1 地方政府雾霔治理的政策工具效果差异和空间} 溢出效应分析

为了更全面地对假说 1-2 进行实证检验, 本文 同时采用空间静态空间杜宾 (Spatial Durbin Model, $\mathrm{SDM}$ ) 和动态杜宾模型 (DSDM) 实证估计, 政府环 保立法 (law)、执法 ( enf ) 和支出 ( inv ) 对雾霧污染 的影响效果见表 2 。由表可知,与静态空间杜宾模 型比较,动态空间杜宾模型估计的拟合程度更好, 本文将主要基于动态空间杜宾模型估计进行分 
表 1 变量的描述性统计

Table 1 Descriptive statistics of variables

\begin{tabular}{|c|c|c|c|c|c|c|c|c|c|}
\hline \multirow{2}{*}{ 变量 } & \multirow{2}{*}{ 单位 } & \multicolumn{4}{|c|}{ 省(市、区)层面 } & \multicolumn{4}{|c|}{ 地市层面 } \\
\hline & & 均值 & 最小值 & 最大值 & 标准差 & 均值 & 最小值 & 最大值 & 标准差 \\
\hline $\operatorname{smog} / S M O G$ & PM2.5/( $\left.\mu \mathrm{g} / \mathrm{m}^{3}\right)$ & 31.89 & 4.81 & 81.98 & 16.67 & 38.95 & 7.12 & 86.74 & 16.28 \\
\hline law/LAW & 环保立法/件 & 27.22 & 0.00 & 208.00 & 29.84 & 3.79 & 0.00 & 110.00 & 9.01 \\
\hline enf & 执法案件/(例/人) & 0.53 & 0.01 & 5.95 & 0.62 & - & - & - & - \\
\hline$i n v / I N V$ & 环保占比/\% & 3.00 & 0.85 & 6.73 & 1.08 & 2.96 & 0.13 & 31.82 & 2.19 \\
\hline$e y / E Y$ & 人均 GDP/万元 & 1.19 & 0.28 & 3.18 & 0.64 & 1.39 & 0.27 & 8.37 & 0.86 \\
\hline$s c i / S C I$ & 科学技术支出占比/\% & 1.53 & 0.22 & 7.20 & 1.31 & 1.64 & 0.07 & 20.68 & 1.44 \\
\hline$s / S$ & 二产占比/\% & 46.98 & 19.26 & 61.50 & 7.94 & 50.18 & 14.95 & 90.97 & 10.49 \\
\hline$u r b / U R B$ & 城镇化/\% & 50.48 & 13.89 & 89.60 & 14.58 & 52.53 & 7.08 & 100.00 & 18.81 \\
\hline$f d i / F D I$ & 外资存量占比/\% & 15.32 & 0.79 & 78.83 & 13.41 & 26.73 & 0.00 & 168.35 & 28.18 \\
\hline$h / H$ & 人力资本/\% & 8.64 & 6.04 & 12.30 & 0.99 & 1.24 & 0.40 & 4.48 & 0.52 \\
\hline $\operatorname{den} / D E N$ & 人口密度/(人/km²) & 436.84 & 7.40 & 3826.2 & 630.11 & 482.68 & 21.00 & 2648.00 & 336.65 \\
\hline
\end{tabular}

析。本文重点关注本地政府环保立法 (law)、环保 执法 ( enf ) 、环保支出 $(i n v)$ 以及邻近地区环保立 法(Wlaw)、环保执法( Wenf) 环保支出 (Winv) 对 本地雾霔的影响效果。law 的估计系数都是显著为 负值,这意味着本地政府环保立法有效地控制了当 地雾䨪问题。但是, 本地环保执法 (enf) 对雾䨪污 染的控制作用并不显著; 这是因为, 2013 年以后中 国才开始专门针对雾䨪问题进行专项执法检查, 政 府严格雾䨚执法短期内对地区经济的抑制作用较 强 ${ }^{[4]}$, 近年来经济增速明显放缓更是使得地方政府 严格执法压力增大, 从而削弱了环保执法的积极作 用; 同时,2016年中国才试行省以下环保机构监测 监察执法垂直管理制度改革, 并开始中央环保督察 工作, 对本文研究期内环保执法治霾效果的影响也 比较有限。本地环保支出 ( inv) 对雾䨪的治理效果 显著。邻地政府环保立法、执法和支出的影响来 看, Wenf 和 Winv 系数值都为负, 但 Wenf 系数未通 过显著检验, Winv 则比较有效。这是因为, 当前中 国多数区域环保立法的协调机制尚未有效建立, 地 方政府环保立法多以本地利益出发进行规制治理, 邻近地区环保立法的增加会显著提高地区之间雾 皬治理协调成本, 降低本地雾霉治理的效果 ${ }^{[51]}$; 同 时,在地方政府之间以资源获取、经济发展为主要 竞争目标局面下, 面对邻近地区环保立法加强、雾 䨪治理成效的显现, 本地政府则存在策略性降低雾
䨪治理以吸引资源流人的冲动, 也不利于本地雾䨪 污染的改善 ${ }^{[4,29]}$ 。

其他因素影响方面,根据 $e y$ 和 $e y^{2}$ 的系数可以 判断, 地区经济发展对雾䨪污染的影响呈现出比较 显著的 “ $U$ ”型非线性关系, 黄寿峰 ${ }^{[27]}$ 也得到了类似 的研究结论。这是因为,在经济起飞的初始阶段, 地区经济多以粗放型为主, 此时雾䨪污染比较严 重,但是政府治理雾䨪时从规模和技术调整的效果 都会比较好 ${ }^{[47]}$, 因此雾霍治理受到经济增长带来的 压力并不明显; 但是, 当地区经济水平达到相当的 水平之后, 雾䨪治理会受到产业转型升级和环保技 术瓶颈难以突破等因素带来的压力 ${ }^{[39]}$, 治理难度也 随之加大。邻近地区经济增长的影响, 根据表 2 可 知 $W e y$ 系数值大多显著为负、 $W e y^{2}$ 是正数但是只 在 $e n f$ 模型中通过统计显著检验, 这是因为, 各地经 济发展竞争和增长方式的相对粗放, 邻近地区通过 竞争降低了本地雾䨪治理压力 ${ }^{[29]}$ 。各地产业结构 $(s)$ 以及邻近区域产业结构 $(W s)$ 在 $l a w$ 和 $i n v$ 模型 方程中系数值大多显著为负值, 但在 enf 模型中部 分显著。该分析结果与预期存在偏差,这是因为, 虽然本地区的工业化进程恶化了雾霳污染, 但是也 加强了地区雾䨪治理的规模效应以及绿色技术发 挥; 而且，由于地区之间存在的正向空间溢出效应， 邻近地区工业发展的雾䨪治理水平提升, 对本地雾 皬污染有一定的治理优化作用。对科技发展因素 
表 2 政策工具差异与空间溢出效应估计

Table 2 Estimation of the effect of different types of measures and spatial spillovers

\begin{tabular}{|c|c|c|c|c|c|c|c|c|}
\hline \multirow{2}{*}{ 变量 } & \multicolumn{2}{|c|}{ 解释变量: 执法案件数(enf) } & \multirow{2}{*}{ 变量 } & \multicolumn{2}{|c|}{ 解释变量: 环保立法(law) } & \multirow{2}{*}{ 变量 } & \multicolumn{2}{|c|}{ 解释变量: 环保财政支出 (inv) } \\
\hline & SDM模型 & DSDM模型 & & SDM模型 & DSDM模型 & & SDM模型 & DSDM模型 \\
\hline \multirow[t]{2}{*}{$\operatorname{smog}_{t-1}$} & & $0.092 * *$ & $\operatorname{smog}_{t-1}$ & & $0.109 * * *$ & $\operatorname{smog}_{t-1}$ & & $0.103^{* * *}$ \\
\hline & & $(2.56)$ & & & $(2.78)$ & & & $(2.67)$ \\
\hline \multirow[t]{2}{*}{ enf } & 0.163 & 0.246 & law & $-0.021 * * *$ & $-0.021 * * *$ & inv & $-0.464 *$ & $-0.458^{*}$ \\
\hline & $(0.63)$ & $(0.94)$ & & $(-3.28)$ & $(-3.25)$ & & $(-1.71)$ & $(-1.66)$ \\
\hline \multirow[t]{2}{*}{ ey } & $-7.276^{* *}$ & $-5.556 * *$ & ey & $-2.821 * *$ & $-2.954 * * *$ & ey & $-2.349 *$ & $-1.421 *$ \\
\hline & $(-2.13)$ & $(-2.06)$ & & $(-2.45)$ & $(-2.73)$ & & $(-1.92)$ & $(-1.73)$ \\
\hline \multirow[t]{2}{*}{$e y^{2}$} & $2.106^{* *}$ & $1.581^{*}$ & $e y^{2}$ & $1.622 *$ & $1.896^{*}$ & $e y^{2}$ & $1.039 *$ & $1.219^{*}$ \\
\hline & $(2.42)$ & $(1.74)$ & & $(1.69)$ & $(1.84)$ & & $(1.74)$ & $(1.77)$ \\
\hline \multirow[t]{2}{*}{$s$} & $-0.037 *$ & -0.029 & s & -0.028 & $-0.043 *$ & s & $-0.155 * *$ & $-0.149 * *$ \\
\hline & $(-1.86)$ & $(-1.63)$ & & $(-1.54)$ & $(-1.96)$ & & $(-2.39)$ & $(-2.10)$ \\
\hline \multirow[t]{2}{*}{$s c i$} & $-0.243^{*}$ & $-0.256^{*}$ & $s c i$ & $-0.225^{*}$ & $-0.203 *$ & $s c i$ & $-0.388 * *$ & -0.206 \\
\hline & $(-1.88)$ & $(-1.92)$ & & $(-1.73)$ & $(-1.70)$ & & $(-1.99)$ & $(-1.52)$ \\
\hline \multirow[t]{2}{*}{$u r b$} & 0.016 & $0.064 *$ & $u r b$ & $0.059 *$ & $0.066^{*}$ & $u r b$ & $0.130^{*}$ & $0.117^{*}$ \\
\hline & (1.08) & (1.68) & & (1.71) & $(1.70)$ & & (1.74) & (1.66) \\
\hline \multirow[t]{2}{*}{$f d i$} & $-0.040^{*}$ & $-0.065^{* *}$ & $f d i$ & $-0.017 *$ & $-0.015^{*}$ & $f d i$ & $-0.071^{*}$ & $-0.070^{*}$ \\
\hline & $(-1.68)$ & $(-2.16)$ & & $(-1.68)$ & $(-1.67)$ & & $(-1.92)$ & $(-1.87)$ \\
\hline \multirow[t]{2}{*}{ den } & -0.002 & -0.002 & den & $-0.006 * *$ & $-0.005^{*}$ & den & $-0.013 * *$ & $-0.015^{* *}$ \\
\hline & $(-0.82)$ & $(-0.60)$ & & $(-1.99)$ & $(-1.74)$ & & $(-2.29)$ & $(-2.13)$ \\
\hline \multirow[t]{2}{*}{ Wenf } & -0.551 & -0.635 & Wlaw & $0.043 * * *$ & $0.043 * * *$ & Winv & $-0.313^{*}$ & $-0.384 *$ \\
\hline & $(-1.04)$ & $(-1.19)$ & & (3.79) & $(3.81)$ & & $(-1.73)$ & $(-1.77)$ \\
\hline \multirow[t]{2}{*}{ Wey } & $-0.474 *$ & $-0.463^{*}$ & Wey & $-0.968^{*}$ & $-0.892 *$ & Wey & $-0.586^{*}$ & -0.443 \\
\hline & $(-1.77)$ & $(-1.67)$ & & $(-1.86)$ & $(-1.67)$ & & $(-1.65)$ & $(-1.45)$ \\
\hline \multirow[t]{2}{*}{$W e y^{2}$} & $2.055^{*}$ & $1.600^{*}$ & $W e y^{2}$ & 0.406 & 0.609 & $W e y^{2}$ & 2.304 & 1.842 \\
\hline & $(1.82)$ & (1.75) & & (1.29) & (1.43) & & (1.15) & $(0.79)$ \\
\hline \multirow[t]{2}{*}{$W s$} & -0.070 & -0.074 & $W s$ & $-0.104 *$ & $-0.153 * *$ & $W s$ & $-0.218 * *$ & $-0.164 *$ \\
\hline & $(-1.07)$ & $(-1.09)$ & & $(-1.80)$ & $(-2.48)$ & & $(-2.11)$ & $(-1.68)$ \\
\hline \multirow[t]{2}{*}{ Wsci } & 0.354 & $0.563 *$ & Wsci & 0.274 & 0.212 & Wsci & 0.441 & 0.506 \\
\hline & (1.46) & (1.68) & & (1.62) & (1.03) & & $(0.64)$ & $(1.22)$ \\
\hline \multirow[t]{2}{*}{ Wurb } & -0.017 & -0.014 & Wurb & -0.069 & $-0.213 * *$ & Wurb & $-0.507 *$ & $-0.435^{*}$ \\
\hline & $(-0.30)$ & $(-0.28)$ & & $(-0.84)$ & $(-2.22)$ & & $(-1.93)$ & $(-1.67)$ \\
\hline \multirow[t]{2}{*}{$W f d i$} & 0.044 & $0.175^{* *}$ & $W f d i$ & 0.052 & 0.045 & $W f d i$ & 0.039 & 0.014 \\
\hline & $(0.58)$ & (1.97) & & $(0.77)$ & $(0.77)$ & & $(0.37)$ & $(0.12)$ \\
\hline \multirow[t]{2}{*}{ Wden } & $-0.010^{*}$ & -0.005 & Wden & -0.005 & -0.004 & Wden & -0.011 & -0.013 \\
\hline & $(-1.77)$ & $(-0.88)$ & & $(-0.73)$ & $(-0.62)$ & & $(-1.12)$ & $(-1.14)$ \\
\hline \multirow[t]{2}{*}{$\rho$} & $0.779 * * *$ & $0.787 * * *$ & $\rho$ & $0.590 * * *$ & $0.589 * * *$ & $\rho$ & $0.559 * * *$ & $0.562 * * *$ \\
\hline & (22.39) & (22.72) & & (15.04) & $(14.80)$ & & (11.50) & (11.14) \\
\hline$R^{2}$ & 0.313 & 0.320 & $R^{2}$ & 0.337 & 0.355 & $R^{2}$ & 0.372 & 0.381 \\
\hline $\log L$ & -585.757 & -888.657 & $\log L$ & -888.657 & -915.679 & $\log L$ & -676.972 & -607.577 \\
\hline
\end{tabular}

注: 括号内的数值表示相应估计系数的 $t$ 统计值, $* * * * * *$ 分别表示在 $1 \% 、 5 \% 、 10 \%$ 的水平显著,下同; 为更加系统地考察地区空间关联影 响, 此处空间权重为地理与经济权重嵌套的混合权重矩阵。 
进行分析发现, 本地技术进步 ( sci ) 能够明显降低 雾䨪浓度。这是因为, 伴随着技术水平发展, 当地 能源效率会显著提升, 雾䨪排放强度也有所减低, 从而降低雾霹污染 ${ }^{[6]}$;邻近地区技术发展 $(W s c i)$ 的 估计系数虽为正值却大多不显著, 这是因为, 绿色 技术在邻近地区之间正向外溢而促进地区雾䨪浓 度整体下降的良性互动行为尚未出现。城镇化 ( urb) 在增加当地雾皬污染上相对显著; 刘晨跃 等 ${ }^{[13]}$ 的研究也发现类似现象,伴随城镇化进程推进, 地区能源消耗的增加、房地产业投资的繁荣、基础 设施的不断建设和交通拥堵压力的增加, 都会给本 地雾䨪治理带来较大压力。邻近地区城镇化 ( Wurb) 的系数显示, 邻区城镇化发展对本地雾䨪 存在抑制作用, 这是因为, 邻区城镇化进程加快对 本地人口有一定的吸引, 间接降低了本地雾霧污染 压力。外资 $(f d i)$ 的系数为负且十分显著, 邵帅 ${ }^{[6]}$ 的 研究也得到类似结果, 外资企业通过绿色技术的正
向溢出作用和严格环境标准的作用降低了当地雾 䨪浓度。然而邻区外资 $(W f d i)$ 系数却有所不同, 虽 都是正值但未通过显著性检验; 这是因为, 在邻近 地区之间在外资上存在激烈竞争的格局下,邻近地 区外资发展使得高端产业进人本地的机会进一步 下降,并不利于本地产业转型和绿色技术发展。在 大部分方程中, 人口密度 $(d e n)$ 显著降低了污染; 这 是因为, 人口密度的增加带来了地区人口和产业的 集聚,使得雾䨪治理投资等规模效应更加显著 ${ }^{[48]}$, 有 利于雾䨪污染的降低; 同时, 人口集聚增加也使得 当地政府面临的环保與论和监督压力增加,地方政 府环保力度也会进一步提升 ${ }^{[3]}$ 。

\section{2 基于门槛效应的分析}

表 3 显示了动态面板门槛估计对科技门槛效应 的估计(受版面限制, 本文不再报告 $F$ 检验和门槛值 的置信区间）。其中, $A R(1) 、 A R(2)$ 和 Sargan 等检验 结果显示,本文的工具变量选择基本合适。由于表

表 3 科学技术支出门槛效应的估计

Table 3 Estimation of the threshold effect of science and technology expenditure

\begin{tabular}{|c|c|c|c|c|c|c|c|c|c|}
\hline \multirow{2}{*}{ 变量 } & \multicolumn{3}{|c|}{ 环保执法(enf) } & \multicolumn{3}{|c|}{ 环保立法(law) } & \multicolumn{3}{|c|}{ 环保投资(inv) } \\
\hline & $(0,0.530]$ & $(0.530,2.250]$ & $(2.250,+\infty)$ & $(0,0.360]$ & $(0.360,4.440]$ & $(4.440,+\infty)$ & $(0,1.530]$ & $(1.530,3.740]$ & $(3.740,+\infty)$ \\
\hline \multirow{2}{*}{$\operatorname{smog}_{i,-1}$} & $0.149 *$ & $0.150^{*}$ & $0.038^{*}$ & 0.132 & 0.124 & $0.162 *$ & -0.003 & -0.095 & -0.167 \\
\hline & (1.67) & (1.69) & $(1.72)$ & $(1.44)$ & (1.34) & $(1.72)$ & $(-0.01)$ & $(-0.36)$ & $(-0.62)$ \\
\hline \multirow[t]{2}{*}{ gov } & 0.228 & $2.007 * * *$ & -0.229 & $0.027 * * *$ & $-0.075^{*}$ & $-0.093 *$ & -0.163 & 0.709 & $-1.018^{*}$ \\
\hline & $(0.47)$ & $(2.79)$ & $(-1.42)$ & $(3.05)$ & $(-1.66)$ & $(-1.76)$ & $(-0.28)$ & (1.24) & $(-1.70)$ \\
\hline \multirow[t]{2}{*}{ ey } & $-2.462 *$ & $-2.463^{*}$ & -2.792 & $-2.155^{* *}$ & $-2.289 * *$ & -1.539 & $-5.812^{*}$ & $-7.001 *$ & $-5.756^{*}$ \\
\hline & $(-1.74)$ & $(-1.76)$ & $(-1.61)$ & $(-2.49)$ & $(-2.52)$ & $(-1.35)$ & $(-1.76)$ & $(-1.92)$ & $(-1.72)$ \\
\hline \multirow[t]{2}{*}{$e y^{2}$} & $0.778^{*}$ & $0.778^{*}$ & 0.914 & 0.605 & $0.666^{*}$ & 0.472 & 1.115 & 1.197 & 0.604 \\
\hline & $(1.75)$ & $(1.75)$ & $(0.89)$ & (1.61) & (1.66) & (1.47) & $(1.56)$ & $(1.60)$ & $(0.30)$ \\
\hline \multirow[t]{2}{*}{$s$} & $-0.136^{*}$ & $-0.137^{*}$ & $-0.127^{*}$ & $-0.193 * * *$ & $-0.192 * * *$ & $-0.207 * * *$ & $-0.206^{* *}$ & $-0.212 * *$ & $-0.203 * *$ \\
\hline & $(-1.82)$ & $(-1.82)$ & $(-1.70)$ & $(-2.68)$ & $(-2.66)$ & $(-2.86)$ & $(-2.00)$ & $(-2.08)$ & $(-1.99)$ \\
\hline \multirow[t]{2}{*}{$f d i$} & $-0.114 *$ & $-0.115^{*}$ & -0.001 & -0.056 & -0.049 & -0.071 & -0.007 & 0.047 & -0.087 \\
\hline & $(-1.72)$ & $(-1.72)$ & $(-0.91)$ & $(-0.82)$ & $(-0.71)$ & $(-1.02)$ & $(-0.03)$ & $(0.23)$ & $(-0.43)$ \\
\hline \multirow[t]{2}{*}{ den } & $-0.007 *$ & $-0.007^{*}$ & $-0.007^{*}$ & $-0.007^{*}$ & $-0.007^{*}$ & $-0.008 * *$ & -0.013 & -0.014 & -0.015 \\
\hline & $(-1.75)$ & $(-1.75)$ & $(-1.67)$ & $(-1.81)$ & $(-1.79)$ & $(-2.00)$ & $(-1.42)$ & $(-1.46)$ & $(-1.62)$ \\
\hline \multirow[t]{2}{*}{$A R(1)$} & -3.299 & -3.321 & -3.021 & -3.335 & -3.300 & -3.277 & -2.734 & -2.712 & -2.754 \\
\hline & $-[0.001]$ & [0.001] & {$[0.001]$} & {$[0.001]$} & {$[0.001]$} & [0.001] & {$[0.006]$} & [0.006] & {$[0.005]$} \\
\hline \multirow[t]{2}{*}{$A R(2)$} & 2.564 & 2.632 & 2.441 & 2.776 & 2.744 & 2.667 & 2.230 & 2.225 & 2.327 \\
\hline & [0.113] & {$[0.146]$} & [0.108] & [0.155] & [0.152] & [0.149] & [0.125] & [0.130] & [0.144] \\
\hline \multirow[t]{2}{*}{ Sargan } & 24.206 & 24.321 & 22.446 & 25.315 & 25.277 & 25.082 & 24.991 & 24.877 & 25.021 \\
\hline & [1.000] & {$[1.000]$} & {$[1.000]$} & {$[1.000]$} & {$[1.000]$} & {$[1.000]$} & [0.895] & [0.894] & [0.895] \\
\hline
\end{tabular}

注: 括号内的数值表示相应估计系数的 $t$ 统计值。AR(1)、AR(2)和Sargan 检验系数[ ]内是 $p$ 值。下同。 
2 已经系统考察了其他控制变量对地区雾䨪的影响 效果, 且表 3 与表 2 类似, 不再重复。表 3 主要分析 当地区科技水平存在一定差异时,地方政府不同治 理工具对雾䨪的影响效果。根据上述结果, 地区科 技水平较弱时,地方政府通过环保立法、执法和投 资等手段对于雾䨪的治理效果不强, 甚至可能加剧 当地污染; 主要是因为科技投人少或科技水平低使 得环保技术不能充分发展, 造成政府治理投资的资 源浪费和效率低下问题严重 ${ }^{[39]}$; 同时, 立法和执法对 雾䨪的治理效果也可能被污染企业的寻租所规避, 反而加剧雾䨪污染 ${ }^{[49]}$ 。地区科技实力较强时, 环保 立法 (law) 和环保投资 ( inv ) 的治霾效果也会比较 显著, 但执法 (enf) 的治䨪效果并不明显; 这可能 是, 当地科技水平较高时, 地区环境规制也会更加 严格 ${ }^{[4]}$, 社会公众和组织的环保意识也会有所加强, 有助于企业资源合理配置 ${ }^{\left[{ }^{[}\right]}$, 强化了政府政策的治 皬效果。所以, 只有地区科技达到一定水平以后， 地方政府治理措施对雾䨪的抑制作用才能有效显
现,这与本文假说 3 基本符合。以本文政府治理能 够有效降低雾皬的最低科技门槛值 $(2.250 \%)$ 为准， 2016 年只有北京、上海、天津等 8 个发达的省 (市、 区)超过该水平; 这表明,中国多数地区仍需要继续 加大科技投人, 以有效助推地方政府治䨪效果的 提升。

表 4 报告了城镇化门槛效应的估计。多数变量 系数与表 3 相似,此处重点报告地区城镇化水平存 在差异时,政府不同治理工具对雾䨝的影响效果。 综合以上结果, 从环保立法、环保投资政策措施来 看,地方政府治理雾䨪存在比较显著的城镇化门槛 效应,基本验证了本文假说 4 的存在性。在城镇化 水平比较低时,地方政府的环境治理行为并不会有 效减少雾皬。这是因为, 在城镇化较低的水平上, 整个社会的环保的意识较为薄弱,环保技术也比较 落后,为经济增长而竞争使得政府倾向于降低环境 规制标准或者尽可能减少环保投资 ${ }^{[13]}$, 较低的环保 标准或者环保投资一定程度刺激了高能耗企业生

\section{表 4 城镇化门槛效应的估计}

Table 4 Estimation of urbanization threshold effect

\begin{tabular}{|c|c|c|c|c|c|c|c|c|c|}
\hline \multirow{2}{*}{ 区间 } & \multicolumn{3}{|c|}{ 环保执法(enf) } & \multicolumn{3}{|c|}{ 环保立法(law) } & \multicolumn{3}{|c|}{ 环保投资(inv) } \\
\hline & $(0,45.760]$ & $(45.760,86.500]$ & $(86.500,+\infty)$ & $(0,68.710]$ & $(68.710,81.550]$ & $(81.550,+\infty)$ & $(0,67.370]$ & $(67.370,82.010]$ & $(82.010,+\infty)$ \\
\hline \multirow[t]{2}{*}{$\operatorname{smog}_{i, t-1}$} & 0.154 & 0.157 & 0.159 & 0.199 & 0.203 & 0.205 & 0.332 & 0.256 & 0.210 \\
\hline & (1.11) & (1.14) & (1.16) & $(1.57)$ & $(1.58)$ & $(1.60)$ & (1.62) & $(1.26)$ & $(1.03)$ \\
\hline \multirow[t]{2}{*}{ gov } & 1.788 & 0.226 & 0.418 & $0.027 * * *$ & $-0.103^{*}$ & $-0.090^{*}$ & -0.115 & $2.500 * * *$ & $-3.642 * *$ \\
\hline & $(1.22)$ & $(0.58)$ & $(1.05)$ & $(2.71)$ & $(-1.93)$ & $(-1.79)$ & $(-0.23)$ & $(2.60)$ & $(-2.57)$ \\
\hline \multirow[t]{2}{*}{ ey } & $-10.385^{* *}$ & $-8.965 * *$ & $-9.040 * *$ & $-10.967 * * *$ & $-10.922 * * *$ & $-10.937 * * *$ & $-11.056^{*}$ & $-12.148^{* *}$ & $-13.111 * *$ \\
\hline & $(-2.49)$ & $(-2.13)$ & $(-2.15)$ & $(-2.81)$ & $(-2.79)$ & $(-2.82)$ & $(-1.84)$ & $(-2.05)$ & $(-2.22)$ \\
\hline \multirow{2}{*}{$e y^{2}$} & $2.157^{* *}$ & $1.804 *$ & $1.817^{*}$ & $2.391 * *$ & $2.383^{* *}$ & $2.374 * *$ & 2.363 & 2.483 & 2.494 \\
\hline & $(2.17)$ & (1.79) & (1.80) & $(2.54)$ & $(2.53)$ & $(2.50)$ & (1.39) & (1.49) & $(1.51)$ \\
\hline \multirow[t]{2}{*}{$s$} & -0.066 & -0.074 & $-0.082^{*}$ & -0.116 & -0.119 & -0.127 & $-0.168 *$ & -0.137 & $-0.164^{*}$ \\
\hline & $(-1.36)$ & $(-1.47)$ & $(-1.95)$ & $(-1.46)$ & $(-1.47)$ & $(-1.50)$ & $(-1.69)$ & $(-1.40)$ & $(-1.63)$ \\
\hline \multirow[t]{2}{*}{$f d i$} & -0.079 & -0.075 & -0.078 & -0.104 & -0.107 & -1.09 & $-0.260^{*}$ & -0.210 & -0.219 \\
\hline & $(-0.79)$ & $(-0.76)$ & $(-0.79)$ & $(-1.13)$ & $(-1.14)$ & $(-1.16)$ & $(-1.67)$ & $(-1.30)$ & $(-1.36)$ \\
\hline \multirow[t]{2}{*}{ den } & $-0.008^{*}$ & $-0.009 * *$ & $-0.009 * *$ & -0.004 & -0.004 & -0.004 & $-0.039 * * *$ & $-0.036^{* * *}$ & $-0.037 * * *$ \\
\hline & $(-1.87)$ & $(-2.04)$ & $(-2.08)$ & $(-0.93)$ & $(-0.92)$ & $(-0.95)$ & $(-3.55)$ & $(-3.37)$ & $(-3.44)$ \\
\hline \multirow[t]{2}{*}{$A R(1)$} & -3.774 & -3.558 & -3.449 & -3.472 & -3.311 & -3.287 & -2.844 & -2.920 & -2.941 \\
\hline & [0.001] & {$[0.001]$} & [0.001] & {$[0.001]$} & [0.001] & {$[0.001]$} & {$[0.004]$} & [0.004] & {$[0.004]$} \\
\hline \multirow[t]{2}{*}{$A R(2)$} & 2.611 & 2.544 & 2.494 & 2.844 & 2.582 & 2.573 & 2.517 & 2.523 & 2.525 \\
\hline & [0.167] & {$[0.157]$} & {$[0.150]$} & {$[0.164]$} & {$[0.160]$} & [0.153] & [0.170] & [0.174] & [0.178] \\
\hline \multirow[t]{2}{*}{ Sargan } & 23.822 & 22.882 & 22.772 & 26.022 & 23.774 & 23.463 & 26.233 & 26.821 & 26.833 \\
\hline & [1.000] & {$[1.000]$} & {$[1.000]$} & {$[1.000]$} & {$[1.000]$} & {$[1.000]$} & [0.914] & [0.923] & [0.925] \\
\hline
\end{tabular}


产, 进而加剧雾䨪污染。然而, 城镇化水平较高时, 地方政府环境治理效果更明显。这是因为, 高城镇 化社会将提出更高的雾䨪治理标准 ${ }^{[14]}$, 环保技术的 充分应用、环境治理的规模效应发挥也都能有效提 升政府环保投资的治䨪效率。以本文政府治理能 够有效降低雾䨪的最低城镇化门槛值 $(68.710 \%)$ 为 准,2016年仅有上海、北京、天津、广东等 7 个发达的 省(市、区)超过该水平; 这表明, 中国多数地区仍需 要加快推进城镇化进程, 以有效助推地方政府治霾 效果的提升。

\section{3 城市层面的稳健性检验}

通过省(市、区)层面的实证估计对本文假说 1-4 进行验证,地方政府雾䨪治理存在明显的政策效果 差异,地方政府雾皬治理也存在相对显著的空间关 联和科技、城镇化门槛。然而, 雾雺污染的分布具 有局部性分布特点,受到经济活动以及地理因素的 影响,同一省级区域内部不同城市的雾䨪污染态势 都会存在一定差异,省(市、区)计量结果较宏观; 同 时,假说 2 主要研究地方政府环境治理行为及其对
雾䨪污染的空间溢出效应,基于城市层面的估计可 以更好地考察地方政府之间的竞争与合作互动。 所以,除了省 (市、区) 的层面实证估计,本文进一步 以 2007-2016年中国 217 个城市为研究对象,再次 对前文估计结果进行稳健检验。鉴于地市政府政 府仅有环保支出数据, 无法对假说 1 进行稳健检 验。表 5 是分别基于地理、经济和混合权重角度,城 市层面对假说 2 计量估计的结果; 表 6 是基于地市 层面数据,分别从科技门槛效应、城镇化门槛角度 进行估计的结果。表 5 的估计结果表明,地市政府 通过环保投资有效控制了地区雾皬污染问题,并且 邻近地方政府的环保投资对本地雾霳污染有显著 抑制作用，进一步证明了假说 2 的存在。基于表 6 科技门槛估计分析发现,当地区科学技术支出占比 高于 $1.2 \%$ 时,当地政府的环保投资可以比较有效地 降低雾䨪污染; 反之则加重。基于表 6 城镇化门槛 估计分析发现,当地区城镇化比例高于 $79.9 \%$ 时,当 地政府的环保投资可以十分有效地控制雾霧污染; 反之则加剧。门槛效应的稳健性检验再次验证了

表 5 城市层面 3 种权重的稳健性检验

Table 5 Robustness test of three weights at the city level

\begin{tabular}{|c|c|c|c|c|c|c|}
\hline 变量 & \multicolumn{2}{|c|}{ 地理权重 } & \multicolumn{2}{|c|}{ 经济权重 } & \multicolumn{2}{|c|}{ 混合权重 } \\
\hline$S M O G_{t-1}$ & $0.050 * * *$ & (4.48) & $0.105 * * *$ & $(4.88)$ & $0.035 * * *$ & (2.63) \\
\hline$I N V$ & $-0.063^{*}$ & $(-1.74)$ & $-0.074 * *$ & $(-1.96)$ & $-0.089 * * *$ & $(-2.75)$ \\
\hline$E Y$ & $1.168^{* *}$ & $(2.11)$ & $1.897 *$ & (1.71) & $1.052 *$ & (1.76) \\
\hline$E Y^{2}$ & $-0.139 * *$ & $(-2.12)$ & -0.147 & $(-1.12)$ & $-0.147 * *$ & $(-2.02)$ \\
\hline$S$ & -0.024 & $(-1.48)$ & $-0.060 *$ & $(-1.86)$ & -0.001 & $(-0.75)$ \\
\hline$S C I$ & $-0.094 *$ & $(-1.85)$ & $-0.297 * * *$ & $(-2.61)$ & $-0.130 * *$ & $(-1.96)$ \\
\hline$U R B$ & $0.019 *$ & (1.73) & $0.021^{*}$ & (1.75) & $0.024 *$ & (1.90) \\
\hline$F D I$ & $-0.008^{*}$ & $(-1.82)$ & $-0.076 * * *$ & $(-4.71)$ & -0.004 & $(-1.38)$ \\
\hline$D E N$ & -0.002 & $(-1.51)$ & -0.001 & $(-1.16)$ & $-0.003 *$ & $(-1.69)$ \\
\hline$W I N V$ & -0.079 & $(-0.96)$ & $-0.421 * *$ & $(-2.37)$ & $-0.215^{*}$ & $(-1.67)$ \\
\hline$W E Y$ & -0.105 & $(-1.09)$ & -0.231 & $(-1.09)$ & $-2.249 *$ & $(-1.83)$ \\
\hline$W E Y^{2}$ & 0.017 & (1.11) & 0.371 & $(1.57)$ & $0.285^{* *}$ & (2.00) \\
\hline$W S$ & -0.009 & $(-0.92)$ & $-0.006^{*}$ & $(-1.90)$ & $-0.004 *$ & $(-1.72)$ \\
\hline WSCI & $-0.357 * * *$ & $(-2.76)$ & -0.057 & $(-1.14)$ & $-0.553 * * *$ & $(-3.11)$ \\
\hline$W U R B$ & 0.024 & $(0.78)$ & 0.077 & (1.43) & $0.055^{*}$ & (1.74) \\
\hline$W F D I$ & -0.018 & $(-0.93)$ & $-0.010 * *$ & $(-2.09)$ & $-0.023 * *$ & $(-2.28)$ \\
\hline$W D E N$ & 0.010 & $(1.62)$ & 0.006 & (1.56) & 0.007 & (1.48) \\
\hline$\rho$ & $0.977 * * *$ & (139.82) & $0.519 * *$ & (17.14) & $0.955 * * *$ & $(94.65)$ \\
\hline$R^{2}$ & \multicolumn{2}{|c|}{0.360} & \multicolumn{2}{|c|}{0.308} & \multicolumn{2}{|c|}{0.373} \\
\hline $\log L$ & \multicolumn{2}{|c|}{-404.673} & \multicolumn{2}{|c|}{-527.599} & \multicolumn{2}{|c|}{-428.164} \\
\hline
\end{tabular}


表 6 城市层面门槛效应的稳健性检验

Table 6 Robustness test of threshold effect at the city level

\begin{tabular}{|c|c|c|c|c|c|c|c|}
\hline 科技支出区间 & $(0,0.320]$ & $(0.320,1.200]$ & $(1.200,+\infty)$ & 城镇化区间 & $(0,71.880]$ & $(71.880,79.900]$ & $(79.900,+\infty)$ \\
\hline \multirow[t]{2}{*}{$S M O G_{t-1}$} & $1.572 * * *$ & $2.089 * * *$ & $2.006 * * *$ & $S M O G_{t-1}$ & $0.802 * * *$ & $0.742 * * *$ & $0.713 * *$ \\
\hline & (2.88) & (3.48) & (3.34) & & (2.79) & (2.59) & (2.48) \\
\hline \multirow[t]{2}{*}{$I N V$} & 0.016 & $0.059^{* *}$ & $-0.312^{* * *}$ & $I N V$ & 0.031 & $0.153^{* * *}$ & $-0.467 * *$ \\
\hline & (1.28) & (2.39) & $(-2.92)$ & & (1.38) & $(4.51)$ & $(-2.33)$ \\
\hline \multirow[t]{2}{*}{$E Y$} & $9.493 *$ & $14.381 * *$ & $13.713 * *$ & $E Y$ & $2.543^{*}$ & 1.985 & 1.754 \\
\hline & (1.81) & $(2.50)$ & $(2.38)$ & & $(1.78)$ & $(1.61)$ & $(0.54)$ \\
\hline \multirow[t]{2}{*}{$E Y^{2}$} & -0.156 & $-0.883 * *$ & $-0.837^{*}$ & $E Y^{2}$ & -0.006 & -0.031 & -0.045 \\
\hline & $(-1.25)$ & $(-1.97)$ & $(-1.87)$ & & $(-0.02)$ & $(-0.11)$ & $(-0.16)$ \\
\hline \multirow[t]{2}{*}{$S$} & 0.068 & $-0.099 * *$ & $-0.097 * *$ & $S$ & -0.059 & $-0.088^{* *}$ & $-0.087^{* *}$ \\
\hline & $(1.50)$ & $(-2.08)$ & $(-2.02)$ & & $(-0.31)$ & $(-2.27)$ & $(-2.25)$ \\
\hline \multirow[t]{2}{*}{$F D I$} & $-0.298 * *$ & $-0.417 * * *$ & $-0.398 * * *$ & $F D I$ & $-0.119^{*}$ & -0.100 & -0.095 \\
\hline & $(-2.31)$ & $(-2.95)$ & $(-2.81)$ & & $(-1.68)$ & $(-1.42)$ & $(-1.34)$ \\
\hline \multirow[t]{2}{*}{$D E N$} & $-0.122 * * *$ & $-0.161 * * *$ & $-0.155^{* * *}$ & $D E N$ & $-0.063 * * *$ & $-0.058 * *$ & $-0.056^{* *}$ \\
\hline & $(-2.90)$ & $(-3.50)$ & $(-3.36)$ & & $(-2.80)$ & $(-2.60)$ & $(-2.50)$ \\
\hline
\end{tabular}

本文假说 3 和假说 4 的合理性。同时, 表 5-6 中其他 变量的估计结果也与省 (市、区) 层面数据的估计结 果基本类似,说明本文计量估计的稳健性。

\section{6 结论和政策建议}

\section{1 结论}

本文以中国 2003-2016年30个省 (市、区) 、 2007-2016年 217 个城市的面板数据为基础, 综合 利用动态面板空间和动态面板门槛等计量方法, 较 为系统地考察了地方政府环境治理措施对雾䨪污 染的影响效果。主要结论如下:

(1) 从政策工具效果来看,地方政府针对雾霧 治理的立法数量和强度都有所增强, 不断完善的环 保立法对中国雾䨪治理产生了显著的积极影响。 同时,地方政府对于环境保护的投资规模也稳步提 升,环保投资的雾䨪治理效果也十分显著。然而, 受到雾皬专项执法政策实施较晚、地方政府平衡环 保执法与经济发展等因素影响,地方政府环保执法 抑制雾䨪污染的作用不甚显著。

(2) 从空间关联效应来看, 本地和邻近地区政 府环保执法、环保投资的加强, 将通过积极的空间 外溢效应而对周边地区雾䨪污染产生一定的抑制 作用; 然而, 由于地方政府间环保政策的协调成本 上升, 地方政府环保立法加强对周边地区雾霧治理 产生负面影响。
(3) 从门槛效应来看, 当地区科学技术和城镇 化水平都比较低时,地方政府的各种环境治理措施 都很难有效改善本地雾䨪污染; 而当地区科学技术 和城镇化处于较高水平时,通过更高规格的雾䨪治 理标准制定、环保意识的有效提升等积极因素作用 的发挥,地方政府的环保立法、环保投资对当地雾 皬治理具有显著的积极影响。

\section{2 政策建议}

在本文主要结论的基础上,给出以下政策建议:

(1) 严格落实环境治理行为,完善雾䨪治理领 域防治和监督体系。各地政府以及相关责任部门 要严格实施雾䨪专项减排计划、有效构建治理体 系,保证政府环保执法的权威性,系统保障环境治 理执法工作的全面展开。同时,环保部门要加强对 环保执法不同阶段信息的透明化处理,全面构建环 保部门执法督察体系中的约谈、通报和问责机制， 坚决遏制环保领域腐败现象的滋生; 地方财政部门 要按时公布环保财政资金支出的明细,对于雾霧治 理投人的人力、物力和财力进行严格把控监督, 优 化环保执法部门内部的专业职能分工和权力制衡, 进一步优化完善环保部门内部的监督约束制度。

(2)完善各地区间空间联动防治机制, 把握生 态环境保护和经济发展的协同发展。地方政府不 仅要对本区域重点开发、优化开发、限制开发、禁止 
开发的规划布局有明确认识,还要有效构建地方政 府之间的环境治理协调沟通机制,通过对各地区资 源利用情况以及污染情况等方面进行联动防治, 科 学制定严格控制雾䨪规制的最低标准,把控资源利 用率。同时,由于地区雾䨪污染具有显著的空间关 联溢出,要切实改变地方政府考核体系中经济发展 比重过高的现象,加大环保考核在地方考核中的比 重,预防环境规制“逐底竞争”现象的出现，坚持“总 体谋划、久久为功” 的理念, 在资源环境承载力方面 的监测建立全面的预警保护机制。

(3) 优化城镇化发展模式, 推动绿色技术创 新。地方政府设计制定城镇化发展模式时, 要坚持 “绿水青山就是金山银山”的理念, 要更多从地区绿 色发展、生态协调的角度进行规划设计,有效提高 区域资源、能源的利用效率, 推动城镇化的绿色转 型升级。同时,地方政府要更加注重绿色技术创新 在环境治理方面的应用,监督和规范企业的生产技 术标准, 大力推动高效清洁技术在企业实际生产中 的应用; 积极探索社会绿色生态产品体系构建,大 力推广自身可持续发展生态产品在全社会的应用, 全面推动新能源技术和传统能源改进技术的有效 提升。

\section{参考文献(References):}

[1] 生态环境部. 2018 年中国环境公报[EB/OL]. (2019-05-22) [2019-11-29]. http://hjj.changchun.gov.cn/ywdt/zwdt/gnyw/20190 5/P020190530340283177962.pdf. [Ecological Environment. China Environmental Bulletin 2018[EB/OL]. (2019-05-22) [201911-29]. http://hjj.changchun.gov.cn/ywdt/zwdt/gnyw/201905/P020 190530340283177962. pdf.]

[2] 石敏俊. 雾䨪治理的经济成本与社会成本 [N/OL]. (2017-0124) [2020-09-03]. http://www.rmlt.com.cn/2017/0124/457460.shtml. [Shi M J. The Economic Cost and Social Cost of Haze Control [EB/OL]. (2017- 01-24) [2020- 09- 03]. http://www.rmlt.com.cn/ 2017/0124/457460.shtml.]

[3 ] 李子豪. 公众参与对地方政府环境治理的影响: 2003-2013年 省际数据的实证分析[J]. 中国行政管理, 2017, (8): 102-108. [Li Z H. The impact of public participation on local government's environmental governance: An analysis of provincial data 20032013[J]. Chinese Public Administration, 2017, (8): 102-108.]

[4] 张华. 地区间环境规制的策略互动研究: 对环境规制非完全执 行普遍性的解释[J]. 中国工业经济, 2016, (7): 74-90. [Zhang H.
Strategic interaction of regional environmental regulation: An explanation on the universality of incomplete enforcement of environmental regulation[J]. China Industrial Economics, 2016, (7): 7490.]

[ 5 ] Grossman G M, Krueger A B. Environmental Impacts of a North American Free Trade Agreement[R]. NBER Working Paper No.3914, 1991.

[6]郡帅, 李欣, 曹建华, 等. 中国雾䨪污染治理的经济政策选择 基于空间溢出效应的视角[J]. 经济研究, 2016, 51(9): 73-88. [Shao S, Li X, Cao J H, et al. China's economic policy choices for governing smog pollution based on spatial spiliover effects[J]. Economic Research Journal, 2016, 51(9): 73-88.]

[7] Ma Y R, Ji Q, Fan Y. Spatial linkage analysis of the impact of regional economic activities on PM2.5 pollution in China[J]. Journal of Cleaner Production, 2016, 139: 1157-1167.

[8] 孙攀, 吴玉鸣, 鲍曙明, 等. 经济增长与雾曘污染治理: 空间环 境库兹涅茨曲线检验[J]. 南方经济, 2019, (12): 100-117. [Sun $\mathrm{P}, \mathrm{Wu}$ Y M, Bao S M, et al. A study on economic growth and smog pollution: Testing spatial environmental Kuznets Curve Hypothesis in China[J]. South China Journal of Economics, 2019, (12): 100-117.]

[9] 修国义, 朱悦, 王俭. 产业集聚, 人口规模与雾霧污染: 基于省 际面板数据的实证[J]. 统计与决策, 2020, 36(7): 61-65. [Xiu G Y, Zhu Y, Wang J. Industrial agglomeration, population size and haze pollution: An empirical study based on inter-provincial panel data[J]. Statistics and Decision, 2020, 36(7): 61-65.]

[10] 徐盈之, 刘琦. 产业集聚对雾䨪污染的影响机制: 基于空间计量 模型的实证研究[J]. 大连理工大学学报(社会科学版), 2018, 39 (3): 24-31. [Xu Y Z, Liu Q. The influence mechanism of industrial agglomeration on haze pollution: An empirical study based on spatial econometric model[J]. Journal of Dalian University of Technology (Social Sciences), 2018, 39(3): 24-31.]

[11] Li G D, Fang C L, Wang S J, et al. The effect of economic growth, urbanization, and industrialization on fine particulate matter (PM2.5) concentrations in China[J]. Environmental Science \& Technology, 2016, 50(21): 11452-11459.

[12] Han L J, Zhou W Q, Li W F, et al. Impact of urbanization level on urban air quality: A case of fine particles (PM2.5) in Chinese cities [J]. Environmental Pollution, 2014, 194: 163-170.

[13] 刘晨跃, 徐盈之. 城镇化如何影响雾䨪污染治理: 基于中介效应 的实证研究[J]. 经济管理, 2017, 39(8): 6-23. [Liu C Y, Xu Y Z. How does urbanization affect the haze pollution control: An empirical study based on mediation effect method?[J]. Business Management Journal, 2017, 39(8): 6-23.]

[14] 王华星, 石大千. 新型城镇化有助于缓解雾䨪污染吗: 来自低碳 城市建设的经验证据[J]. 山西财经大学学报, 2019, 41(10): 15- 
27. [Wang H X, Shi D Q. Dose new urbanization help to alleviate smog pollution: Empirical evidence from low-carbon city construction?[J]. Journal of Shanxi University of Finance and Economics, 2019, 41(10): 15-27.]

[15] 曾浩, 申俊. 省域FDI 与雾皬污染的空间相关性分析 [J]. 江西社 会科学, 2019, 39(10): 50-60. [Zeng H, Shen J. Spatial correlation analysis between provincial FDI and haze pollution[J]. Jiangxi Social Sciences, 2019, 39(10): 50-60.]

[16] 严雅雪, 齐绍洲. 外商直接投资与中国雾䨪污染[J]. 统计研究, 2017, 34(5): 69-81. [Yan Y X, Qi S Z. FDI and haze pollution in China[J]. Statistical Research, 2017, 34(5): 69-81.]

[17] 刘修岩, 董会敏. 出口贸易加重还是缓解中国的空气污染: 基于 PM2.5 和 $\mathrm{SO}_{2}$ 数据的实证检验[J]. 财贸研究, 2017, 28(1) : 7684. [Liu X Y, Dong H M. Does export aggravate or mitigate China' $\mathrm{s}$ air pollution: Based on empirical test of PM2.5 and $\mathrm{SO}_{2}[\mathrm{~J}]$. Finance and Trade Research, 2017, 28(1): 76-84.]

[18] Wang Y T, Sun M X, Yang X C. Public awareness and willingness to pay for tackling smog pollution in China: A case study[J]. Journal of Cleaner Production, 2016, 112(2): 1627-1634.

[19] 初钊鹏, 市晨, 刘昌新, 等. 雾䨪污染、规制治理与公众参与的演 化仿真研究[J]. 中国人口·资源与环境, 2019, 29(7): 101-111. [Chu Z P, Bian C, Liu C X, et al. Simulation of haze pollution, regulatory governance and public participation based on evolutionary game analysis[J]. China Population, Resources and Environment, 2019, 29(7): 101-111.]

[20] 吕长明, 李跃. 雾霾與论爆发下城市减排差异与大气污染联防 联控[J]. 经济地理, 2017, 37(1): 148-154. [Lv C M, Li Y. City reducing emission difference and joint control of air pollution under public opinion explosion on haze[J]. Economic Geography, 2017, 37(1): 148-154.]

[21] 李欣, 杨朝远, 曹建华. 网络與论有助于缓解雾霧污染吗: 兼论 雾䨪污染的空间溢出效应[J]. 经济学动态, 2017, (6): 45-57. [Li X, Yang C Y, Cao J H. Can the internet public opinion help ease the haze pollution: An the spatial spillover effect of haze pollution[J]. Economic Perspectives, 2017, (6): 45-57.]

[22] 王卉娅, 刘传明, 赵浚竹. 交通拥堵与雾䨪污染: 基于职住平衡 的新视角[J]. 财贸经济, 2018, 39(1): 147-160. [Wang H T, Liu C

M, Zhao J Z. Traffic jam and haze pollution: A new perspective based on jobs-housing balance[J]. Finance and Trade Economics, 2018, 39(1): 147-160.]

[23] Xie R, Wei D H, Han F, et al. The effect of traffic density on smog pollution: Evidence from Chinese cities[J]. Technological Forecasting and Social Change, 2019, 144(2): 421-427.

[24] 钱振华, 刘家华. 关于环境治理的责任伦理反思: 基于中外雾䨪 问题治理的比较分析[J]. 北京科技大学学报(社会科学版), 2015, 31(3): 76-86. [Qian Z H, Liu J H. Ethical reflection on the responsibility of environmental governance: Based on the comparison and analysis of the governance of fog and haze in China and other countries[J]. Journal of University of Science and Technology Beijing (Social Science Edition), 2015, 31(3): 76-86.]

[25] 彭本红, 屠羽. 双重社会资本嵌人视角的雾霹治理机制研究 [J]. 软科学, 2017, 31(5): 75-79. [Peng B H, Tu Y. Study on haze governance mechanisms from the perspective of dual social capital embeddedness[J]. Soft Science, 2017, 31(5): 75-79.]

[26] 李根生, 韩民春. 财政分权、空间外溢与中国城市雾䨪污染: 机 理与证据[J]. 当代财经, 2015, (6): 26-34. [Li G S, Han M C. Fiscal decentralization, spatial spillover and China's urban haze pollution in: Mechanism and evidence[J]. Contemporary Finance \& Economics, 2015, (6): 26-34.]

[27] 黄寿峰. 财政分权对中国雾䨪影响的研究[J]. 世界经济, 2017, 40(2): 127-152. [Huang S F. A study of impacts of fiscal decentralization on smog pollution[J]. The Journal of World Economy, 2017, 40(2): 127-152.]

[28] 吴勋, 白蕾. 财政分权、地方政府行为与雾䨪污染: 基于 73 个城 市 PM2.5 浓度的实证研究[J]. 经济问题, 2019, (3): 23-31. [Wu X, Bai L. Fiscal decentralization, local government behavior and haze pollution: Analysis based on PM2.5 concentration in 73 cities [J]. On Economic Problems, 2019, (3): 23-31.]

[29] 刘华军, 彭芗. 雾䨝污染区域协同治理的“逐底竞争”检验[J]. 资 源科学, 2019, 41(1): 185-195. [Liu H J, Peng Y. “Race to the bottom"test of collaborative management in haze pollution area[J]. Resources Science, 2019, 41(1): 185-195.]

[30] 石庆玲, 郭峰, 陈诗一.雾䨪治理中的“政治性蓝天”: 来自中国 地方“两会”的证据[J]. 中国工业经济, 2016, (5): 40-56. [Shi Q L, Guo F, Chen S Y. "Political Blue Sky" in fog and haze governance: Evidence from the local annual "Two Sessions" in China [J]. China Industrial Economics, 2016, (5): 40-56.]

[31] Chen Y, Schleicher N, Chen Y Z, et al. The influence of governmental mitigation measures on contamination characteristics of PM2.5 in Beijing[J]. Science of the Total Environment, 2014, 490: 647-658.

[32] 李小胜, 束云霞. 环境政策对空气污染控制与地区经济的影响: 基于命令控制型工具的实证[J]. 数理统计与管理, 2020, 39(4): 691-704. [Li X S, Shu Y X. Impact of environmental policy on air pollution control and regional economy: Based on command control tools[J]. Journal of Applied Statistics and Management, 2020, 39(4): 691-704.]

[33] 孙坤金金. 机动车排放标准的雾䨪治理效果研究: 基于断点回归 设计的分析[J]. 软科学, 2017, 31(11): 93-97. [Sun K X. Study on effect of haze treatment on vehicle emission standard: Analysis based on regression discontinuity design[J]. Soft Science, 2017, 31 (11): 93-97. 
[34] 罗知, 李浩然. “大气十条”政策的实施对空气质量的影响[J]. 中 国工业经济, 2018, (9): 136-154. [Luo Z, Li H R. The impact of "atmosphere ten articles" policy on air quality in China[J]. China Industrial Economics, 2018, (9): 136-154.]

[35] 肖巍, 钱箭星. 环境治理中的政府行为 [J]. 复旦学报(社会科学 版), 2003, (3): 73-79. [Xiao W, Qian J X. Government act in environment governance[J]. Fudan Journal (Social Sciences Edition, 2003, (3): 73-79.]

[36] 王波, 郜峰. 雾雺环境责任立法创新研究: 基于现代环境责任的 视角 [J]. 中国软科学, 2015, (3): 1-8. [Wang B, Gao F. Innovations in legislation on haze environmental responsibility: Perspective of modern environmental responsibility[J]. China Soft Science, 2015, (3): 1-8.]

[37] 中华人民共和国国务院. 大气污染防治行动计划[EB/OL]. (2013- 09- 12).http://www.gov.cn/zwgk/2013- 09/12/content_248 6773.htm. [State Council of the PRC. Action Plan for Air Pollution Prevention and Control[EB/OL]. (2013-09-12) http://www.gov.cn/ zwgk/2013-09/12/content_2486773.htm.]

[38] 肖梦然. 雾霳防治的环保执法问题研究[J]. 法制与社会, 2013, (24): 246-246. [Xiao M R. Research on environmental law enforcement of haze prevention and control[J]. Legal System and Society, 2013, (24): 246-246.]

[39] 孙畅. 地方环境监察监测执法垂直管理体制改革: 利弊争论与 改革方向[J]. 中国行政管理, 2016, (12): 13-17. [Sun C. Reform of the vertical management system of local environmental monitoring and enforcement : Advantage, impacts and directions[J]. Chinese Public Administration, 2016, (12): 13-17.]

[40] 原毅军, 孔繁彬. 中国地方财政环保支出、企业环保投资与工业 技术升级[J]. 中国软科学, 2015, (5): 139-148. [Yuan Y J, Kong F B. Local fiscal expenditures on environmental protection, corporate environmental investment and industrial technology upgrading in China[J]. China Soft Science, 2015, (5): 139-148.]

[41] 田淑英, 董玮, 许文立. 环保财政支出、政府环境偏好与政策效 应: 基于省际工业污染数据的实证分析 [J]. 经济问题探索, 2016, (7): 14-21. [Tian S Y, Dong W, Xu W L. Environmental fiscal expenditure, government environmental preference and policy effect: Empirical analysis based on inter-provincial industrial pollution data[J]. Inquiry into Economic Issues, 2016, (7): 14-21.]

[42] Liu J J, Zheng Y F, Li Z Q, et al. Seasonal variations of aerosol optical properties, vertical distribution and associated radiative effects in the Yangtze Delta region of China[J]. Journal of Geophysi- cal Research, 2012, DOI: 10.1029/2011JD016490.

[43] 李子豪, 刘辉煌. FDI 对环境的影响存在门槛效应吗: 基于中国 220 个城市的检验[J]. 财贸经济, 2012, (9): 101-108. [Li Z H, Liu H H. Are there threshold effects of FDI on environment: Evidence from 220 cites in China[J]. Finance and Trade Economic, 2012, (9): 101-108.]

[44] 李子豪. 地区差异、外资来源与 FDI 环境规制效应研究[J]. 中国 软科学, 2016, (8): 89-101. [Li Z H. Regional difference, origin of FDI and environmental regulation effect of FDI[J]. China Soft Science, 2016, (8): 89-101.]

[45] 禄雪焕, 白婷婷. 绿色技术创新如何有效降低雾䨪污染?[J]. 中 国软科学, 2020, (6): 174-182. [Lu X H, Bai T T. How can green technology innovation effectively reduce smog pollution?[J]. China Soft Science, 2020, (6): 174-182.]

[46] Lovely M E, Popp D. Trade, technology, and the environment: Does access to technology promote environmental regulation?[J]. Journal of Environmental Economics \& Management, 2011, 61(1): $16-35$.

[47] 孙宏芃. 制度创新环境与中国绿色技术创新效率[J]. 科技管理 研究, 2016, 36(21): 251-257. [Sun H P. Institutional environment, factors distortion and the innovation technical progress[J]. Science and Technology Management Research, 2016, 36(21): 251-257.]

[48] 陆铭, 冯皓. 集聚与减排: 城市规模差距影响工业污染强度的经 验研究[J]. 世界经济, 2014, 37(7): 86-114. [Lu M, Feng H. Agglomeration and emission reduction: An empirical study on the influence of city size gap on industrial pollution intensity[J]. The Journal of World Economy, 2014, 37(7): 86-114.]

[49] 李子豪, 袁丙兵. 空间关联和门槛效应的地方政府环境治理研 究: 基于廉洁度视角的考察[J]. 中国软科学, 2019, (10): 61-69. [Li Z H, Yuan B B. Government environmental governance research from spatial correlation and threshold effect: Based on the perspective of integrity[J]. China Soft Science, 2019, (10): 61-69.]

[50] 田毕飞, 陈紫若. FDI对中国创业的空间外溢效应[J]. 中国工业 经济, 2016, (8): 40-57. [Tian B F, Chen Z R. Spatial spillover of FDI on entrepreneurship in China[J]. China Industrial Economics, 2016, (8): 40-57.]

[51] 王超峰. 我国区域环境立法机制的构建探究[J]. 宁夏社会科学, 2017, (1): 76-82. [Wang C F. Study on the construction of regional environmental legislation mechanism in China[J]. Social Science in Ningxia, 2017, (1): 76-82.] 


\title{
Environmental policy mechanism of local governments in the treatment of haze pollution : Policy tools, spatial correlations and threshold effects
}

\author{
LI Zihao, YUAN Bingbing \\ (College of International Economics and Trade, Henan University of Economics and Law, Zhengzhou 450046, China)
}

\begin{abstract}
Smog pollution reduction is an important part of the "tough battle for pollution prevention and control". As the key actor of environmental governance, local governments should play a key role in improving the effectiveness of their environmental policies for smog control. Based on the data of 30 provinces (municipalities, autonomous regions) in China's mainland from 2003 to 2016 and the data of 217 cities from 2007 to 2016, this study used dynamic spatial panels and dynamic panel threshold measurement methods to test relevant theoretical hypotheses. The results show that: (1) Different types of measures of the local governments for environmental governance have various degrees of success on smog pollution control. Specifically, environmental protection legislation and environmental protection investment of local governments have more significant effects in reducing smog pollution, while local governments' environmental law enforcement has little effect on the suppression of smog pollution. (2) In terms of spatial correlation, the impact of different measures of local government environmental governance in neighboring areas on local smog pollution is also different. Environmental legislation of neighboring regions has increased local smog pollution through the escalation of coordination costs. Although government environmental law enforcement can reduce smog pollution, the effect is not significant; while environmental protection investment in neighboring areas can significantly reduce local smog pollution through the spatial spillover of smog pollution control. (3) The impact of local government environmental governance on smog pollution has a significant threshold effect. When the level of regional technological development or urbanization is high, local government environmental governance can effectively reduce smog pollution, and vice versa. This study divided government environmental governance into three measures: environmental legislation, law enforcement, and investment. This article detailed the mechanism of government environmental governance actions on smog pollution control, and provided a scientific basis for the government to further improve the environmental governance system and win the war of blue sky defense.
\end{abstract}

Key words: local government; environmental governance; smog pollution; policy tools; spatial correlation; threshold effects 